\title{
Magnetic properties, martensitic and magneto-structural transformations of ferromagnetic Ni-Mn-Sn-Cu shape memory alloys
}

Asma Wederni a, c, Mihail Ipatov b, Eloi.Pineda d, Joan-Josep Suñol c, Lluisa Escoda c, Julián

Maria González b, Safia.Alleg e, Mohamed Khitouni a, Ryszard Żuberekf, Oleksandr Chumak', Adam Nabiałek ${ }^{\dagger}$, Artem Lynnyk ${ }^{\dagger}$

a Laboratory of Inorganic Chemistry, UR 11ES73, University of Sfax, B.P.1171, Sfax 3000, Tunisia.

b Department of Applied Physics, EUPDS, UPV/EHU, 20018, San Sebastian, Spain.

${ }^{\text {c }}$ Department of Physics, University of Girona (P II, EPS), Campus Montilivi s/n, 17071 Girona, Spain.

${ }^{\mathrm{d}}$ Department of Physics, University Politècnica of Catalunya - BarcelonaTech, ESAB, 08660 Castelldefels, Spain.

e Laboratory of Magnetism and Spectroscopy of Solids (LM2S), Department of Physics, Badji Mokhtar-Annaba University, B.P. 12, Annaba 23000 Algeria.

${ }^{\mathrm{f}}$ Institute of Physics, Polish Academy of Sciences, Al. Lotników 32/46, PL-02-668, Warsaw, Poland.

Abstract: The influence of $\mathrm{Cu}$ doping on structural and magnetic properties of $\mathrm{Ni}_{50-\mathrm{x}} \mathrm{Mn}_{36} \mathrm{Sn}_{14-}$ ${ }_{\mathrm{y}} \mathrm{Cu}_{\mathrm{x}, \mathrm{y}}(\mathrm{x}=0,1,2$ and $\mathrm{y}=1$ at. \%) ribbons has been investigated. The crystalline structures of the alloys were resolute by X-ray diffraction (XRD). It is found that the addition of $\mathrm{Cu}$ for $\mathrm{Ni}$ stabilizes austenite phase, whereas, replacing small amount of $\mathrm{Cu}$ for Sn stabilizes modulated martensite phase. Differential scanning calorimetry measurements have proved the characteristic transformation temperatures. The transformation temperatures generally rise as increasing the $\mathrm{Cu}$ content. Therefore, the magneto structural transition, analysed by vibrating sample magnetometry, is tuned by appropriate $\mathrm{Cu}$ doping in the alloys. Likewise, both martensitic and austenitic states exhibit ferromagnetic behaviour.

Keywords: Martensitic transformation, magnetic properties, phase transitions, $\mathrm{Cu}$ additions, Heusler alloys. 


\section{Introduction}

Heusler alloys of Ni-Mn-Sn have gained substantial consideration owing to their useful properties and potential applications as smart materials in view of an environmental friendship. Moreover, these alloys exhibit very interesting shape-memory effect (SMAs). The reversible phase transformation can be considered as the main characteristic of SMAs, that is, it follows a first-order phase transition (FOFT) from a cubic austenite phase with high symmetry to a martensite phase with lower symmetry. By this means, applying external magnetic field or variable temperature result in a martensitic transition (MT). whence the gorgeous functional properties, like the shape memory effect, magnetoresistance response (MR) [1] and the inverse magnetocaloric effect (IMCE) [2]. The significance of magnetic field usage in these alloys offers a new generation of potential actuators and sensors which can be used in high frequency applications [3].

Generally, the magnetic properties of martensite depend on the coexistence of antiferromagnetic and ferromagnetic connections, although the austenite shows ferromagnetic correlations only. Afterward, a huge change in magnetization in the process of martensitic transition is due to a difference in Zeeman energy between the austenite and martensite phases, then a field induced reverse martensitic transformation (FIRMT) happens [4].

A large entropy change is therefore, due to unexpected magnetization change of these alloys at martensitic transition. Consequently, they show a good magnetocaloric effect (MCE). This later, derives from the magnetization jump produced by the variation of magnetic anisotropy upon the martensitic structure transition.

Generally, it is known that changing chemical composition and multiple doping in Heusler alloys disturb directly the MT temperature and magneto-structural properties of the alloys. Mostly, the topic discussed in this paper <<polycrystalline ternary full Heusler alloys heat treated $>>$ have focused on the doping element on the off-stoichiometric Ni-Mn-Sn shape memory alloy to develop quaternary systems, such as Ni-Mn-Sn-Co [5], Ni-Mn-Sn-Cu [6], Ni- 
Mn-Sn-Pd [7]. As motivation, we want to produce such alloys to improve their physical properties and promote their application in the future i.e., adding of fourth element atoms may tailor the microstructure and the magnetic response, the transition temperature and the degree of hysteresis associated with the martensitic transition. Thus, the main objective is to enhance the magnetic properties of alloys. $\mathrm{Cu}$, for instance, has been shown to have a substantial effect on the properties of the Ni-Mn-Sn alloy. It has been revealed that the substitution of $\mathrm{Ni}$ by $\mathrm{Cu}$ in $\mathrm{Ni}_{46-\mathrm{x}} \mathrm{Cu}_{\mathrm{y}} \mathrm{Mn}_{43} \mathrm{Sn}_{11}[8]$ results in a shift of the martensitic transition to a lower temperature while the transition shifts to higher temperature when Cu replaces $\mathrm{Sn}$ in $\mathrm{Ni}_{16} \mathrm{Mn}_{12} \mathrm{Sn}_{4-\mathrm{x}} \mathrm{Cu}_{\mathrm{x}}$ [9]. Strain modulated ferromagnetic resonance (SMFMR) [10] is a unique technique which allows determination of magnetoelastic properties of magnetic shape memory ribbons. The use of this technique let us to determine the magnetoelastic properties of the ribbons.

In the present paper, we have prepared a series of $\mathrm{Mn}_{50-\mathrm{x}} \mathrm{Cu}_{\mathrm{x}, \mathrm{y}} \mathrm{Ni}_{36} \mathrm{Sn}_{14-\mathrm{y}}(\mathrm{x}=$ 0, 1, 2 and y=1) quaternary alloys with Cu substitution for Ni sites and Sn sites. Our aim is to figure out the impact of non-magnetic $\mathrm{Cu}$ addition on phase transformation characteristics, and magnetic structure which help us to appreciate the phase transformation profoundly and design new NiMn-Sn alloys with excellent magnetic properties by doping. In addition, the magnetoelastic and magnetostriction properties of Ni-Mn-Sn and Ni-Mn-Sn-Cu Heusler alloys was studied. Numerous properties including shape memory effect and temperature dependence of magnetism have been examined as well.

\section{Experimental procedure}

Nominal compositions with atomic percentage (at. \%) of $\mathrm{Ni}_{50-x} \mathrm{Mn}_{36} \mathrm{Sn}_{14} \mathrm{Cu}_{\mathrm{x}}(x=0,1$, and 2 ) and $\mathrm{Ni}_{50} \mathrm{Mn}_{36} \mathrm{Sn}_{13} \mathrm{Cu}_{1}$ alloys was elaborated by the non-consumable Buhler MAM-1 arc melting under argon atmosphere using high-purity elements (> 99.98 \%). An additional 2 wt.\% of manganese was added to fulfil losses related to its evaporation during fabrication progression. Each ingot was melted five times to guarantee an initial homogeneity and found 
into a water-cooled copper mold to obtain a massive alloy with a round shape. The obtained ingot was sealed into a quartz cylinder under a vacuum of $10^{-4}$ Torr and were evicted, at room temperature, into a rotating copper wheel, with $40 \mathrm{~ms}^{-1}$ surface velocity. Melt spinning was achieved under Argon air and ribbons alloys were obtained. The microstructure, morphology and experimental structure of the alloys were examined by a scanning electron microscope using a Zeiss DSM 960A functioned at $30 \mathrm{kV}$, attached with an energy dispersive spectrometry (EDX) device (Carl Zeiss, Oberkochen, Germany). The X-ray diffraction (XRD) studies were made to verify the crystallographic structure of the spun-ribbons, at room temperature, on a Panalytical Empyrean diffractometer in a $(\theta-\theta)$ Bragg-Brentano geometry, by means of a radiation font of $\mathrm{Cu}-\mathrm{K} \alpha$ (with wave length of $\lambda=1.5406 \mathrm{~A}^{\circ}$ ). The refinement of crystalline structures are made by means of Maud software, which is founded on Rietveld method [11]. Crystal Structures of the austenite to martensite were attained by differential scanning calorimetry (DSC) in a DSC822 Mettler-Toledo calorimeter. Thereby, thermal cycling experiments, were achieved under argon atmosphere, thru a cooling and heating rate of 10 $\mathrm{K} / \mathrm{min}$. Thermomagnetic measurements were done by means of a vibrating sample magnetometer (VSM-Versa Lab, QD). Zero-field-cooling (ZFC), field-cooling (FC) and fieldheating $(\mathrm{FH})$ protocols, in a temperature range from $0 \mathrm{~K}$ up to $400 \mathrm{~K}$ and an applied magnetic field up to 5 Tesla. From SMFMR technique, we investigated the magnetoelastic properties of $\mathrm{Ni}_{50} \mathrm{Mn}_{36} \mathrm{Sn}_{14}$ and $\mathrm{Ni}_{48} \mathrm{Mn}_{36} \mathrm{Sn}_{14} \mathrm{Cu}_{2}$ samples at room temperature. We used conventional $\mathrm{X}$ band EPR spectrometer with magnetic field variation (frequency $100 \mathrm{kHz}$, amplitude $10^{-1}$ - 100 Oe) equipped with the additional system for the strain modulation (frequency $48 \mathrm{kHz}$, amplitude $\left.10^{-6}-10^{-5}\right)$

\section{Results and discussion}

\subsection{Structure and microstructure}


Fig. 1 shows the x-ray diffraction patterns of $\mathrm{Ni}_{50-\mathrm{x}} \mathrm{Mn}_{36} \mathrm{Sn}_{14} \mathrm{Cu}_{\mathrm{x}}$ alloys $(\mathrm{x}=0,1$ and 2$)$ and $\mathrm{Ni}_{50}$ $\mathrm{Mn}_{36} \mathrm{Sn}_{13} \mathrm{Cu}_{1}$ measured at room temperature. The structure of the samples was of nearly the similar pattern except for small differences in the peak intensities and angles. All the diffraction patterns were successfully recognized with the austenite structure. This is owing to the existence of (111) and (311) superlattice diffraction peaks which confirms the high order of L2 2 structure. Therefore, the XRD pattern corresponding to the melt-spun ribbons disclose a high symmetry L2 1 structure austenite phase. The lattice parameter a is $0.598 \mathrm{~nm}, 0.583 \mathrm{~nm}$ and $0.578 \mathrm{~nm}$ for $\mathrm{x}=0,1$, and 2 alloys, respectively and space group Fm-3m. The value of $a$ is declined when the $\mathrm{Cu}$ content is decreased. This effect could be assigned to the replacement of larger atomic radius $\mathrm{Ni}(0.162 \mathrm{~nm})$ by the smaller atomic radius of $\mathrm{Cu}(0.157 \mathrm{~nm})$ [12]. The high/low degree of order might be attributed to the high/low vacancy concentration [13] .

Regarding to the occupation of crystallographic sites in these types of alloys; for stoichiometric Ni2MnSn Heusler alloys Ni, Mn, Ni, and Sn occupy (0, 0, 0), (0.25, 0.25, 0. 25), (0.5, 0.5, 0.5), and $(0.75,0.75,0.75)$ sites, respectively [14]. Whereas, in off-stoichiometric $\mathrm{Ni}_{2} \mathrm{Mn}_{1+\mathrm{x}} \mathrm{Sn}_{1-\mathrm{x}}$ some Sn sites might be occupied by the excess of Mn atoms. Thus, Mn atoms can have Mn atoms as adjacent neighbours along the [110] directions. Then Mn-Mn interatomic distance, become smaller than that in the stoichiometric compound [2]. Figure 2 shows the XRD patterns of $\mathrm{Ni}_{50} \mathrm{Mn}_{36} \mathrm{Sn}_{13} \mathrm{Cu}_{1}$ alloy measured at room temperature. The diffractogram demonstrates a modulated martensitic phase, which is confirmed to be five-layered monoclinic $10 \mathrm{M}$, with cell parameter: $a=0.448 \mathrm{~nm}, \mathrm{~b}=0.563 \mathrm{~nm}, \mathrm{c}=2.928 \mathrm{~nm}$ and $\beta=92,28^{\circ}$. The Rietveld analysis is the most pertinent analysis for indexing and recognizing these types of diffractograms. These latter are carried out and indexed using Maud software [11]. It is important to note that the theoretical curves fit properly with the experimental ones excepting for the highest of certain peaks. This minor mismatch in the altitude of peaks is conceivably due to the anisotropy and 
texture effect [15].for that, the degree of B2 and L21 ordering in the alloys was assessed using these relations [16]:

$$
\begin{aligned}
& \left(\mathrm{I}_{200} / \mathrm{I}_{220}\right) \exp =\mathrm{S}^{2}{ }_{\mathrm{B} 2}(\mathrm{I} 200 / \mathrm{I} 220) \text { th. } \\
& \left(\mathrm{I}_{111} / \mathrm{I}_{220}\right) \exp =\left[\mathrm{S}_{\mathrm{L} 21}\left(3-\mathrm{S}_{\mathrm{B} 2} / 2\right)\right]^{2}\left(\mathrm{I}_{111} / \mathrm{I}_{220}\right) \text { th. }
\end{aligned}
$$

where the I (hkl) refer to the Bragg peak’s intensity, Miller indices (hkl) and the suffixes 'exp’ represent experimentally obtained intensity values and 'th' represent theoretically simulated ones, respectively. SB2 and SL21 correspond to the degree of B2 and L21 ordering, respectively. SB2 and SL21 determined for each alloy are listed in Table 1. It can be noticed that however high L21 ordering until 85\% is achieved, atomic disorder of $15-18 \%$ exists in the alloys. This behaviour was seen by R.Modak et all [17].

The morphology of the fracture cross section and free surface of the attained ribbons are presented in Fig.4.The micrographs shows that the samples were entirely crystalline, the ribbon flakes (10-15 $\mu \mathrm{m}$ of width) have a similar morphology. Small equiaxed grains were found in fig.1(a)-(c) to be crystallized in a thin layer from the wheel side. In fact, this layer is one that illustrates the main differences in microstructure between the four compositions. Then, the wheel surface of the last one (fig.1(d)) clearly present the lamellar microstructure of the martensite. Heusler alloys produced by melt spinning shows a typical columnar structure in the fracture cross section (fig.1(a'”)-(d'”). This is a sign of the quick crystallization and fast kinetics progress of the samples. The chemical structure of the obtained ribbons was checked by Energy dispersive X-ray spectroscopy (EDX) which is frequently coupled with SEM; these results are listed in Table 2. All of the ribbons had a chemical composition near to the respective composition for each of them. Ribbons are flimsy and easy to cleave in such direction.

\subsection{Thermal analysis}

Shape-memory alloys (SMAs) are a unique family of metals that undergo a solid-to-solid transformation and can exhibit large recoverable strains introduced at low temperature, simply 
by heating the material through a transformation temperature. To study the thermal stability of alloys and to be able to follow the transitions of phases carried out, one must resort to the XRD results. One knows that thermal hysteresis is a typical characteristic for the martensitic transition due to the first-order nature of the transition [18]. Hence, in order to notice the martensite-austenite transition, the DSC scans of $\mathrm{Ni}_{50-\mathrm{x}} \mathrm{Mn}_{36} \mathrm{Sn}_{14} \mathrm{Cu}_{\mathrm{x}}(\mathrm{x}=0,1$ and 2) ribbons should be performed by heating from room temperature at a critical temperature of As. Whereas the DSC scan of $\mathrm{Ni}_{50} \mathrm{Mn}_{36} \mathrm{Sn}_{13} \mathrm{Cu}_{1}$ alloy might be performed by cooling from room temperature, starting from a critical temperature of Ms. The corresponding DSC results are given in Fig.3. The high temperature causes the atoms to arrange themselves into the most compact and regular pattern possible resulting in a rigid cubic arrangement. These Heusler alloys display a firstorder structural transformation, for which Ms increases with increasing $\mathrm{Cu}$ content. We can notice here that Ms increases bit by bit by substituting Ni by Cu from 194.09 to $228.31 \mathrm{~K}$. Nevertheless, replacing Sn by 1at\% of Cu notices an abrupt increase in Ms from 194.09 to reach a value of $325.02 \mathrm{~K}$. One visibly notices that the $\mathrm{Ms}$ for $\mathrm{Ni}_{50-\mathrm{x}} \mathrm{Mn}_{36} \mathrm{Sn}_{14} \mathrm{Cu}_{\mathrm{x}}(\mathrm{x}=0,1$ and 2$)$ is below room temperature. However, the Ms for $\mathrm{Ni}_{50} \mathrm{Mn}_{36} \mathrm{Sn}_{14-\mathrm{x}} \mathrm{Cu}_{\mathrm{x}}(\mathrm{x}=1)$ is in above room temperature. These behaviours can be recognized, distinctly, from XRD studies. Other interesting features extracted from the calorimetric measurements are following thermodynamic parameters. The difference between the temperatures of the peak positions represent the width of the hysteresis $\Delta \mathrm{T}$. The nonappearance of second thermal process disclose us the homogeneity of the as spun-ribbons.

The entropy change can be calculated as of the baseline calorimetry data by the following relationship:

$$
\Delta S=\int_{T_{i}}^{T_{f}} \frac{1}{T}\left(\frac{d Q}{d t}\right)\left(\frac{d T}{d t}\right)^{-1} d T
$$


The integrals were numerically performed from Ms on cooling and from Af on heating to a given temperature $\mathrm{T}$ within the transformation interval after choosing an appropriate base line. Q is the heat exchange determined through the transformation process. It is considered as the area of the DSC peak and can be similarly defined as the enthalpy change $(\Delta H)$ at the temperature that denotes martensitic transformation $\left(T_{0}\right)$, the Gibbs energies of martensitic phase are equivalent to the parent phase [16].

Thus, the thermodynamic equilibrium condition is:

$$
\Delta \mathrm{G}=0=\Delta \mathrm{H}-\mathrm{T}_{0} \Delta \mathrm{S}
$$

we can deduce that:

$$
\mathrm{T}_{0}=\Delta \mathrm{H} / \Delta \mathrm{S}
$$

Whence: $\quad T_{0}=\frac{1}{2}\left(\mathrm{M}_{\mathrm{s}}+\mathrm{A}_{\mathrm{f}}\right)$

Thus, all the thermodynamics parameters and characteristic temperatures $(\Delta H, \Delta S$, As, Af, Ms and Mf) are collected in Table 3.

To further describe this alloy, the average number of valence electrons by atom (e/a) parameter was introduced. One must know that $(e / a)$ has a strong impact on the transformation temperatures for Ni-Mn-Sn Heusler alloys [19].

Electron configurations of the outer shells of different elements is extracted to compute the valence electron concentrations per atom. The $e / a$ ratio is considered to affect the martensite start temperature, Ms, because of the linear relationship between them; Ms declines with declining $e / a$ value [20]. Thereby, the two values of $e / a$ and Ms must follow the rule and increase monotonously [21]. Since the outer atom of Cu contains fewer electrons than Ni or Sn, the substitution of $\mathrm{Ni}$ by $\mathrm{Cu}$ atoms ensures a reduction in the value of $e / a$.

Hence, the value of the starting temperature of martensite diminishes. Recurring to this present work, for $\mathrm{Ni}_{50} \mathrm{Mn}_{36} \mathrm{Sn}_{14}, \mathrm{Ni}_{49} \mathrm{Mn}_{36} \mathrm{Sn}_{14} \mathrm{Cu}_{1}, \mathrm{Ni}_{48} \mathrm{Mn}_{36} \mathrm{Sn}_{14} \mathrm{Cu}_{2}$ and $\mathrm{Ni}_{50} \mathrm{Mn}_{36} \mathrm{Sn}_{13} \mathrm{Cu}_{1}$, the 
obtained value of e/a are 8.08, 7.99, 7.90 and 8.05 respectively. it would be renowned that $e / a$ ratio decreases with gradual $\mathrm{Cu}$-doping, whether by substitution of $\mathrm{Cu}$ for $\mathrm{Ni}$ or for $\mathrm{Sn}$. Analogous findings were create to prove the dependence of $e / a$ on $\mathrm{Ms}$ and $\%$ of $\mathrm{Cu}$-content $[12,20]$.

Obviously, the modest rule between $e / a$ and the $\%$ of $\mathrm{Cu}$-content does not fit the finding showed by B.Gao et al [23]. This can be accredited to the amount of valence electrons for $\mathrm{Cu}$.

Then, the electron configuration of $\mathrm{Cu}$ can be $3 d^{10} 4 s^{1}$ in some ways. We can choose only the $4 \mathrm{~s}$ electron, i.e. 1 electron, as the valence electron of $\mathrm{Cu}$ [22], while other authors measured equally 3d and 4s electrons, i.e. [22,23].

\subsection{Magnetic properties}

In order to accustomed the transition temperatures and the magnetic state of the alloys, the magnetization temperature dependence, $M(T)$, of the ribbons studied in this paper, has been measured in zero-field-cooled (ZFC), field-cooled (FC), and field-heated (FH) methods. First of all, samples were first cooled down to $100 \mathrm{~K}$ in zero field; then applying magnetic field to the sample and the magnetization was measured on heating with the field fixed, hence the obtention of ZFC magnetization curve. The FC (cooling) magnetization was measured while cooling the sample to $100 \mathrm{~K}$ with the similar field, at that point the $\mathrm{FH}$ (heating) magnetization was reached while heating the sample to $400 \mathrm{~K}$ below unmoved field. The temperature dependence of magnetization for all samples recorded 50 Oe and 50 KOe are revealed in Fig.5 and 6, respectively. Through the process of magnetic transition, both FC and ZFC curves exhibits an irreversible behaviour due to an obvious hysteresis lead to forward and inverse MT. The martensitic transformation requires an overheating to transform martensite to austenite and an undercooling to transform austenite to martensite. This behaviour was presented in such a thermal hysteresis in the Field-Cooling _Field Heating sequence. Moreover, under the 
ferromagnetic transition temperature, a deviation between the ZFC and FC curves can be accredited to the coexisting of antiferromagnetic (AFM) coupling in the melt-spun ribbons[9]. It is worth noting that the martensitic transition is a first-order transition. This is represented by thermal hysteresis, which is an emblematic characteristic for the martensitic to austenite transition [18]. The gap detected in the thermal hysteresis of ZFC and FC around 200-220 K (Fig. 5) recommend for us the position of the martensitic start transformation. Similarly, we can understand that the magnetization of the alloys has a minor growth with $\mathrm{Cu}$ addition. Likewise, Kun Zhang et al [9] have stated the same behaviour. Through a supplementary rise of the temperature, the magnetization decreased rapidly for $\mathrm{x}=0,1$ and 2 alloys. The Curie temperature demonstrate a second-order characteristics transition (no thermal hysteresis happens around $\mathrm{T}_{\mathrm{C}}$ ) from the ferromagnetic to the paramagnetic state.

For $\mathrm{Ni}_{50} \mathrm{Mn}_{36} \mathrm{Sn}_{13} \mathrm{Cu}_{1}$, it seems that the martensitic transformation has not thoroughly accomplished. It would be observed that the martensitic transformation temperature will be detected at higher than the Curie temperature and beyond the measurement temperature range, by introducing additional amount of $\mathrm{Cu}$. The martensitic transition can be observed at temperatures above and below the Curie temperature [26]. Curie temperature undergoes a slight change to low temperature under the effect of $\mathrm{Cu}$ addition; $\mathrm{T}_{\mathrm{C}}=307,306,298$ and $294 \mathrm{~K}$ for $\mathrm{x}=0,1,2$ and $\mathrm{y}=1$ respectively. The martensitic transformation temperatures measured from the $\mathrm{M}(\mathrm{T})$ curves are a little bit lower, compared to the results extracted from the DSC measurements (Table3).One can see that Ms=190 K, $198 \mathrm{~K}, 227,5 \mathrm{~K}$ and 324,25 K for $\mathrm{x}=0$, 1, 2 and $\mathrm{y}=1$ respectively. Those divergences might be linked to the experimental conditions/effects such as the application of a magnetic field, or/and the error in measurement from instruments.

Fig.5 and 6 also reflect the existence of the phase transformation. One can note that the martensite is more stable through applying an external magnetic field. It takes more energy from the austenite to martensite. And that makes martensitic transformation temperature shift 
to higher temperature. This is related to the ferromagnetic state of the martensitic phase [27]. Thereupon, hysteresis loops at $50 \mathrm{~K}$ of all the Heusler ribbons are shown in Fig. 7. Hysteresis loops measured at $50 \mathrm{~K}$, emphasize the ferromagnetic ordering of all the Heusler ribbons. From small hysteresis loops, we may perceive the magnetically soft character of austenitic phase, correlated to its highly symmetric cubic structure and low magneto-crystalline anisotropy [28]. This result is in accordance with XRD and refinement results (L21 cubic structure). As expected, austenite phase is magnetically softer than martensite $\left(\mathrm{Ni}_{50} \mathrm{Mn}_{36} \mathrm{Sn}_{13} \mathrm{Cu}_{1}\right)$, shows high saturation magnetization at low fields and fast approach to saturation. This behaviour was also seen by L. González-Legarreta et al [27]. The small hysteresis loops are characteristic of soft magnetic materials. It is acknowledged that hysteresis loop of the austenite phase saturated more quickly than that of the martensite [13].

Figure 8 gives the temperature dependence of electrical resistance measured at $0 \mathrm{~T}$ and $5 \mathrm{~T}$ for $\mathrm{Ni}_{50} \mathrm{Mn}_{36} \mathrm{Sn}_{13} \mathrm{Cu}_{1}$ alloy from 0 to $350 \mathrm{~K}$. For this martensitic phase, the electrical resistance declines slightly as the temperature increases, showing a semiconductor-like behaviour (electrical conductivity value between that of a metal and an insulator). The martensitic transformation brings a sharp jump of electrical resistance, which has also been shown in NiMn-Sn and Ni-Mn-In Heusler alloys[27-29]. It is conveyed that the resistivity of martensite is higher than that of austenite in the Ni-Mn based Heusler alloys [31]. In the vicinity of $325 \mathrm{~K}$, the resistivity drops brusquely, corresponding to the reverse MT. The first order nature transition is confirmed by the existence of thermal hysteresis between heating and cooling processes around MT temperature. So, the diminishing of resistivity values is due to the transformation from martensitic frictions to austenitic in the alloy. The resistivity dependence of magnetic field (up to $9 \mathrm{~T}$ ) at different temperatures for $\mathrm{Ni}_{50} \mathrm{Mn}_{36} \mathrm{Sn}_{13} \mathrm{Cu}_{1}$ is plotted in Fig. 9. The resistivity returns to its initial value of 0 , when, the magnetic field is decreased from $9 \mathrm{~T}$ to $0 \mathrm{~T}$. 
Furthermore, as an incomplete martensite has been transformed to austenite by heating, thus, the residual martensite transforms to austenite by magnetic field.

The magnetoelastic constants of $\mathrm{Ni}_{50} \mathrm{Mn}_{36} \mathrm{Sn}_{14}$ and $\mathrm{Ni}_{48} \mathrm{Mn}_{36} \mathrm{Sn}_{14} \mathrm{Cu}_{2}$ ribbons were taken from SMFMR studies and given in table 4. For uniaxial symmetry, the magnetoelastic tensor has five independent components (in Voigt notation): B11, B12, B13, B33, and B44 [32]. There are no shear strains in our system. Hence, $\varepsilon_{13}=\varepsilon_{23}=\varepsilon_{12}=0$ (in Voigt notation $\varepsilon_{4}=\varepsilon_{5}=\varepsilon_{6}=0$ ), and the B44 magnetoelastic constant does not affect on the free energy change produced by the strains. If the magnetoelastic effect is linked mainly with the variation of the magneto crystalline anisotropy, we can assume that the volume magnetoelastic effect is relatively small. In such case B12 $=-(1 / 2) \mathrm{B} 11$ and B13 $=-(1 / 2) \mathrm{B} 33$, and the magnetoelastic energy in our system is associated with only two independent magnetoelastic constants (e.g. B11 and B33). One can see that the room temperature magnetoelastic constants of the ribbons are relatively small of an order of $10^{6} \mathrm{erg} / \mathrm{cm}^{3}$ for the $\mathrm{Ni}_{50} \mathrm{Mn}_{36} \mathrm{Sn}_{14}$ sample, and of an order of $10^{5} \mathrm{erg} / \mathrm{cm}^{3}$ for the $\mathrm{Ni}_{48} \mathrm{Mn}_{36} \mathrm{Sn}_{14} \mathrm{Cu}_{2}$ sample. The anisotropy of the magnetoelastic constants is negligible. Magnetostriction constants of $\mathrm{Ni}_{50} \mathrm{Mn}_{36} \mathrm{Sn}_{14}$ and $\mathrm{Ni}_{48} \mathrm{Mn}_{36} \mathrm{Sn}_{14} \mathrm{Cu}_{2}$ ribbons $\lambda_{s}\left(B_{\mathrm{ij}}\right)$ are given in table 3, also and were calculated using the formula for saturation magnetostriction of an isotropic sample:

$$
\lambda_{s}\left(B_{i j}\right)=-\frac{B_{i j}}{C_{11}-C_{12}}
$$

We used the elastic constants for the $\mathrm{Ni}_{2} \mathrm{MnSn}$ compound; elastic constant of $\mathrm{C}_{11}=161 \mathrm{GPa}$ and elastic constant of $\mathrm{C}_{12}=137 \mathrm{GPa}$ [33].

\section{Conclusions}

The martensitic transformation temperature, magnetic properties and shape memory characteristics can be meaningfully adjusted by $\mathrm{Cu}$ doping in $\mathrm{Ni}_{50-\mathrm{x}} \mathrm{Mn}_{36} \mathrm{Cu}_{\mathrm{x}, \mathrm{y}} \mathrm{Sn}_{14-\mathrm{y}}$ melt-spun ribbons. It was found that the martensitic transition behaviour and magnetic properties are sensitive to the $\mathrm{Cu}$ content, even in small quantities. XRD measurements demonstrate that the structure undergoes the existence of $\mathrm{L} 2{ }_{1}$ austenitic state when $\mathrm{x}=0,1$ and 2 , and modulated 
martensitic structure with $\mathrm{Cu}$ substitution on the Sn sites. The martensitic start temperature growths from $194 \mathrm{~K}$ to $228 \mathrm{~K}$, by means of the increase of switch of $\mathrm{Cu}$ for $\mathrm{Ni}$. besides, the Curie temperature $T_{C}$ of the austenitic state decreases a little bit. In addition, Cu substitution for Sn convert significantly the martensitic transformation to high temperatures from $194 \mathrm{~K}$ to 325 K. From calorimetric and magnetic measurements, we can make sure that melt-spun ribbons studied in this work are a good ferromagnetic shape memory alloy. For the magnetic field or strain modulation, the magnetoelastic and magnetostriction effects in the as spun ribbons of $\mathrm{Ni}_{50} \mathrm{Mn}_{36} \mathrm{Sn}_{14}$ and $\mathrm{Ni}_{48} \mathrm{Mn}_{36} \mathrm{Sn}_{14} \mathrm{Cu}_{2}$ Heusler alloys at room temperature, is comparatively weak.

\section{Acknowledgements}

The financial support from MAT2016-675967-P MINECO project is acknowledged. This work was partially supported by the national Science Centre of Poland - project 2018/31/B/ST7/04006.

\section{References}

1. Pal D, Ghosh A, Mandal K (2014) Large inverse magnetocaloric effect and magnetoresistance in nickel rich Ni52Mn34Sn14 Heusler alloy. J Magn Magn Mater 360:183-187. https://doi.org/10.1016/J.JMMM.2014.02.023

2. Krenke T, Acet M, Wassermann EF, et al (2005) Martensitic transitions and the nature of ferromagnetism in the austenitic and martensitic states of Ni-Mn-Sn alloys. Phys Rev B - Condens Matter Mater Phys 72:1-9. https://doi.org/10.1103/PhysRevB.72.014412

3. Cai W, Gao L, Gao ZY (2007) Microstructure and phase transformations in a Ni50Mn29Ga16Gd5 alloy with a high transformation temperature. J Mater Sci 42:9216-9220. https://doi.org/10.1007/s10853-007-1893-2 
4. Han ZD, Wang DH, Zhang CL, et al (2007) Erratum: "Low-field inverse magnetocaloric effect in Ni50-xMn39+xSn11 Heusler alloys" [Appl. Phys. Lett. 90, 042507 (2007)]. Appl Phys Lett 90:119902. https://doi.org/10.1063/1.2712506

5. Zhang X, Zhang H, Qian M, Geng L (2018) Enhanced magnetocaloric effect in Ni-MnSn-Co alloys with two successive magnetostructural transformations. Sci Rep 8:8235. https://doi.org/10.1038/s41598-018-26564-5

6. Castillo-Villa PO, Mañosa L, Planes A, et al (2013) Elastocaloric and magnetocaloric effects in Ni-Mn-Sn(Cu) shape-memory alloy. J Appl Phys 113:053506. https://doi.org/10.1063/1.4790140

7. Saha R, Nigam AK (2014) Room temperature inverse magnetocaloric effect in Pd substituted Ni50Mn37Sn13 Heusler alloys. Phys B Condens Matter 448:263-266. https://doi.org/10.1016/J.PHYSB.2014.04.011

8. Das R, Sarma S, Perumal A, Srinivasan A (2011) Effect of Co and Cu substitution on the magnetic entropy change in Ni 46 Mn ${ }_{43}$ Sn 11 alloy. J Appl Phys 109:07A901. https://doi.org/10.1063/1.3540327

9. Zhang K, Tian X, Tan C, et al (2018) Designing a New Ni-Mn-Sn Ferromagnetic Shape Memory Alloy with Excellent Performance by Cu Addition. Metals (Basel) 8:152. https://doi.org/10.3390/met8030152

10. Nesteruk K, Żuberek R, Piechota S, et al (2014) Thin film's magnetostriction investigated by strain modulated ferromagnetic resonance at low temperature. Meas Sci Technol 25:075502. https://doi.org/10.1088/0957-0233/25/7/075502

11. MAUD: a friendly Java program for material analysis using diffraction | IRIS Univ. Trento. https://iris.unitn.it/handle/11572/38076\#.XJDy_bjjLIU. Accessed 19 Mar 2019 
12. Jing C, Yang YJ, Li Z, et al (2013) Tuning martensitic transformation and large magnetoresistance in $\mathrm{Ni} 5_{50}{ }_{x} \mathrm{Cu}_{x} \mathrm{Mn}_{38} \mathrm{Sn}_{12}$ Heusler alloys. J Appl Phys 113:173902. https://doi.org/10.1063/1.4803496

13. Dadda K, Alleg S, Souilah S, et al (2018) Critical behavior, magnetic and magnetocaloric properties of melt-spun Ni50Mn35Sn15ribbons. J Alloys Compd 735:1662-1672. https://doi.org/10.1016/j.jallcom.2017.11.277

14. Krenke T, Moya X, Aksoy S, et al (2007) Electronic aspects of the martensitic transition in Ni-Mn based Heusler alloys. J Magn Magn Mater 310:2788-2789. https://doi.org/10.1016/J.JMMM.2006.10.1139

15. Bachaga T, Daly R, Khitouni M, et al (2015) Thermal and Structural Analysis of Mn49.3Ni43.7Sn7.0 Heusler Alloy Ribbons. Entropy 17:646-657. https://doi.org/10.3390/e17020646

16. Zhao Y., Sheng H., Lu K (2001) Microstructure evolution and thermal properties in nanocrystalline Fe during mechanical attrition. Acta Mater 49:365-375. https://doi.org/10.1016/S1359-6454(00)00310-4

17. Modak R, Raja MM, Srinivasan A (2019) Enhanced magneto-caloric effect upon fourth element (Cu, Fe, Co) substitution in Ni-Mn-Sn thin films. Appl Phys A 125:57. https://doi.org/10.1007/s00339-018-2340-8

18. Ortín J, Delaey L (2002) Hysteresis in shape-memory alloys. Int J Non Linear Mech 37:1275-1281. https://doi.org/10.1016/S0020-7462(02)00027-6

19. Planes A, Mañosa L, Acet M (2009) Magnetocaloric effect and its relation to shapememory properties in ferromagnetic Heusler alloys. J Phys Condens Matter 21:233201. https://doi.org/10.1088/0953-8984/21/23/233201 
20. Chernenko V. (1999) Compositional instability of $\beta$-phase in Ni-Mn-Ga alloys. Scr Mater 40:523-527. https://doi.org/10.1016/S1359-6462(98)00494-1

21. Louidi S, Su??ol JJ, Bachaga T, et al (2014) Thermomagnetic and structural analysis of as-quenched Ni49Co1Mn37Sn13. Phys Status Solidi Curr Top Solid State Phys 11:1116-1119. https://doi.org/10.1002/pssc.201300700

22. Obradó E, Mañosa L, Planes A (1997) Stability of the bcc phase of Cu-Al-Mn shapememory alloys. Phys Rev B 56:20-23. https://doi.org/10.1103/PhysRevB.56.20

23. Gao B, Shen J, Hu FX, et al (2009) Magnetic properties and magnetic entropy change in Heusler alloys Ni50Mn35-x Cu x Sn15. Appl Phys A 97:443-447. https://doi.org/10.1007/s00339-009-5239-6

24. Gautam BR, Dubenko I, Mabon JC, et al (2009) Effect of small changes in Mn concentration on phase transition temperatures and magnetic entropy variations in Ni2Mn0.75Cu0.25Ga Heusler alloys. J Alloys Compd 472:35-39. https://doi.org/10.1016/J.JALLCOM.2008.05.021

25. Esakki Muthu S, Rama Rao N V., Thiyagarajan R, et al (2014) Influence of chemical substitution, magnetic field, and hydrostatic pressure effect on martensitic and intermartensitic transition in bulk $\mathrm{Ni}_{49-\mathrm{x}} \mathrm{Cu}_{x} \mathrm{Mn}_{38} \mathrm{Sn}_{13}(0.5 \leq \mathrm{x} \leq 2)$ Heusler alloys. Appl Phys Lett 104:092404. https://doi.org/10.1063/1.4867234

26. Dubenko I, Ali N, Stadler S, et al (2016) Magnetic, Magnetocaloric, Magnetotransport, and Magneto-optical Properties of Ni-Mn-In-Based Heusler Alloys: Bulk, Ribbons, and Microwires. pp 41-82

27. González-Legarreta L, Caballero-Flores R, Rosa WO, et al (2016) Heusler Alloy Ribbons: Structure, Martensitic Transformation, Magnetic Transitions, and Exchange 
Bias Effect. pp 83-114

28. Hernando B, Llamazares JLS, Santos JD, et al (2009) Grain oriented NiMnSn and NiMnIn Heusler alloys ribbons produced by melt spinning: Martensitic transformation and magnetic properties. J Magn Magn Mater 321:763-768.

https://doi.org/10.1016/j.jmmm.2008.11.105

29. Koyama K, Okada H, Watanabe K, et al (2006) Observation of large magnetoresistance of magnetic Heusler alloy Ni50Mn36Sn14 in high magnetic fields. Appl Phys Lett 89:182510. https://doi.org/10.1063/1.2374868

30. Xuan HC, Zheng YX, Ma SC, et al (2010) The martensitic transformation, magnetocaloric effect, and magnetoresistance in high-Mn content Mn47+xNi43-xSn10 ferromagnetic shape memory alloys. J Appl Phys 108:103920. https://doi.org/10.1063/1.3511748

31. Sharma VK, Chattopadhyay MK, Shaeb KHB, et al (2006) Large magnetoresistance in Ni50Mn34In16 alloy. Appl Phys Lett 89:222509. https://doi.org/10.1063/1.2399365

32. Żuberek R, Chumak OM, Nabiałek A, et al (2018) Magnetocaloric effect and magnetoelastic properties of NiMnGa and NiMnSn Heusler alloy thin films. J Alloys Compd 748:1-5. https://doi.org/10.1016/j.jallcom.2018.03.061

33. Roy T, Pandey D, Chakrabarti A (2016) Probing the possibility of coexistence of martensite transition and half-metallicity in Ni and Co-based full-Heusler alloys: An $a b$ initio calculation. Phys Rev B 93:184102.

https://doi.org/10.1103/PhysRevB.93.184102 
Figures captions:
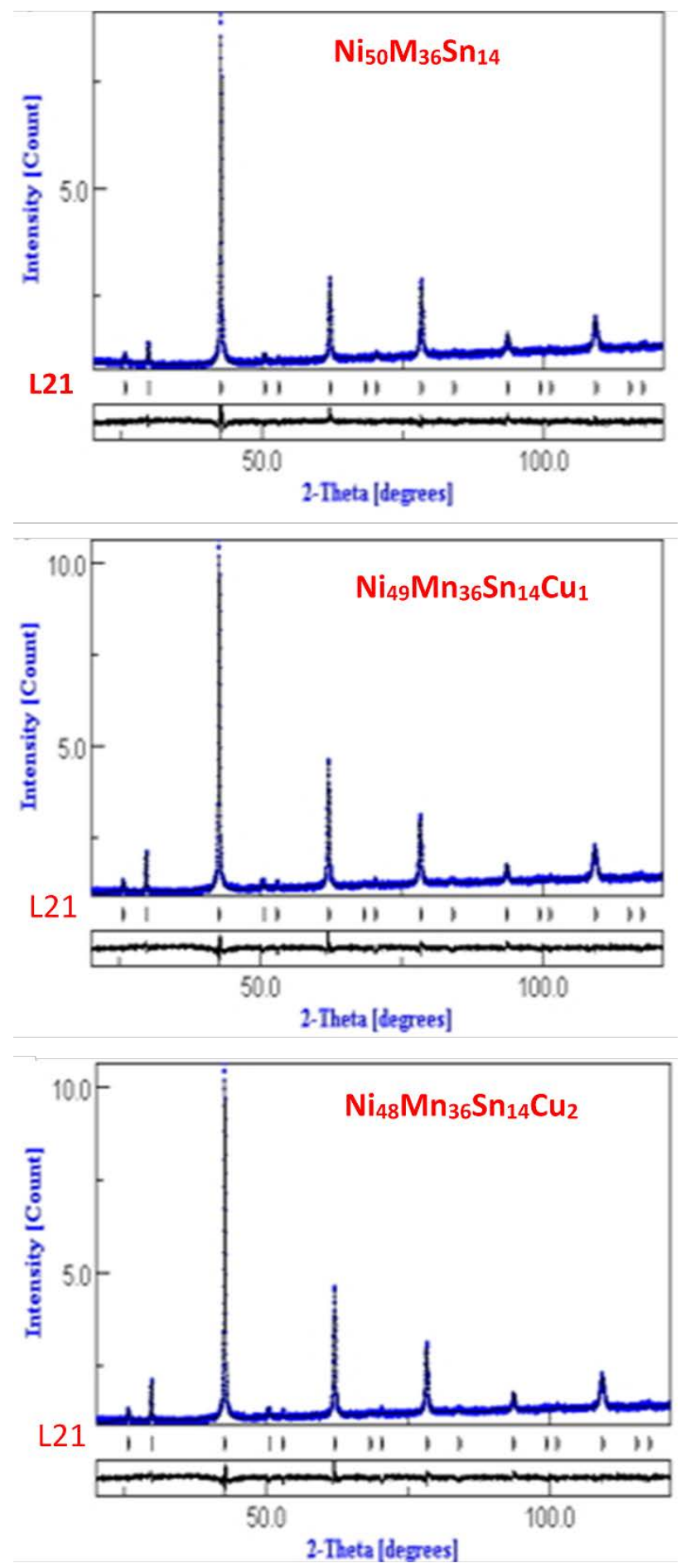

Fig.1 X-ray diffraction patterns of $\mathrm{Ni}_{50-\mathrm{x}} \mathrm{Mn}_{36} \mathrm{Sn}_{14} \mathrm{Cu}_{\mathrm{x}}$ alloys $(\mathrm{x}=0,1$ and 2$)$ measured at room temperature. 


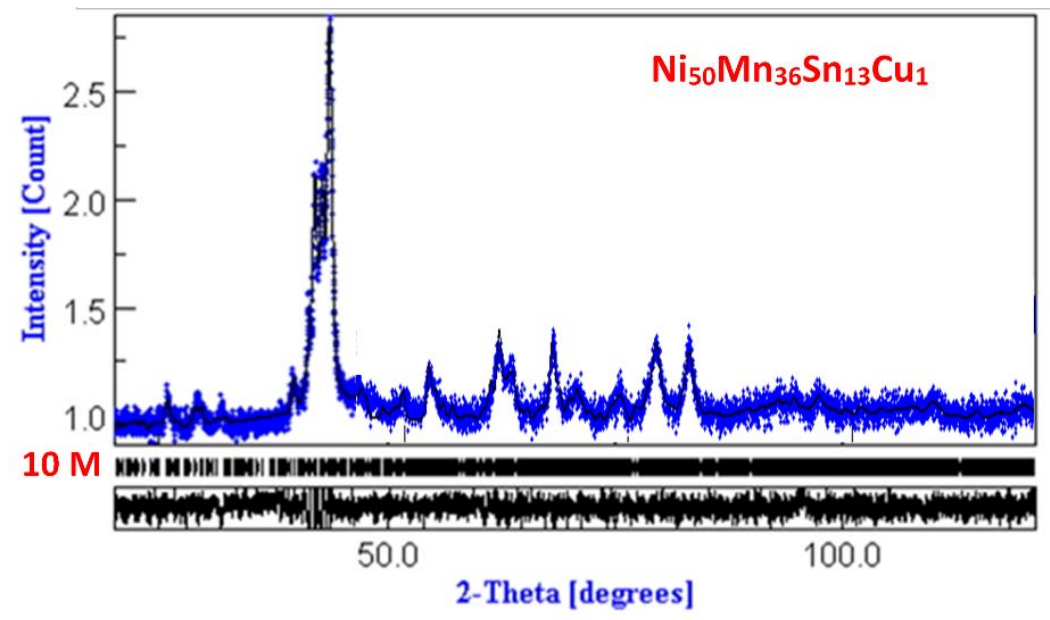

Fig.2 X-ray diffraction patterns of $\mathrm{Ni}_{50} \mathrm{Mn}_{36} \mathrm{Sn}_{13} \mathrm{Cu}_{1}$ measured at room temperature.
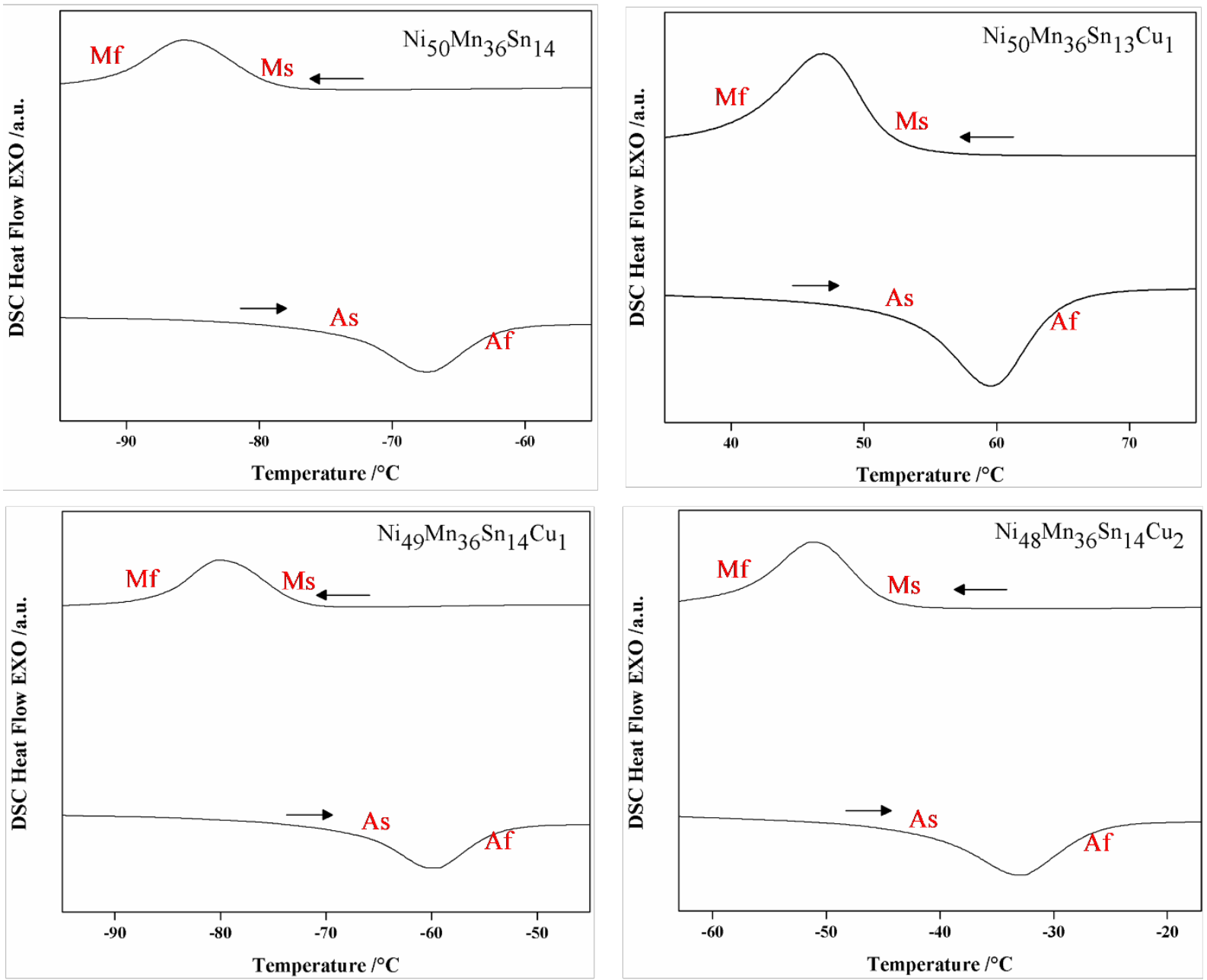

Fig.3 DSC curves during the heating and cooling processes. The reverse martensitic transition (austenitic transition) upon heating start (As) and finish (Af) temperatures and martensitic transition upon cooling start (Ms) and finish (Mf) temperatures are indicated. 

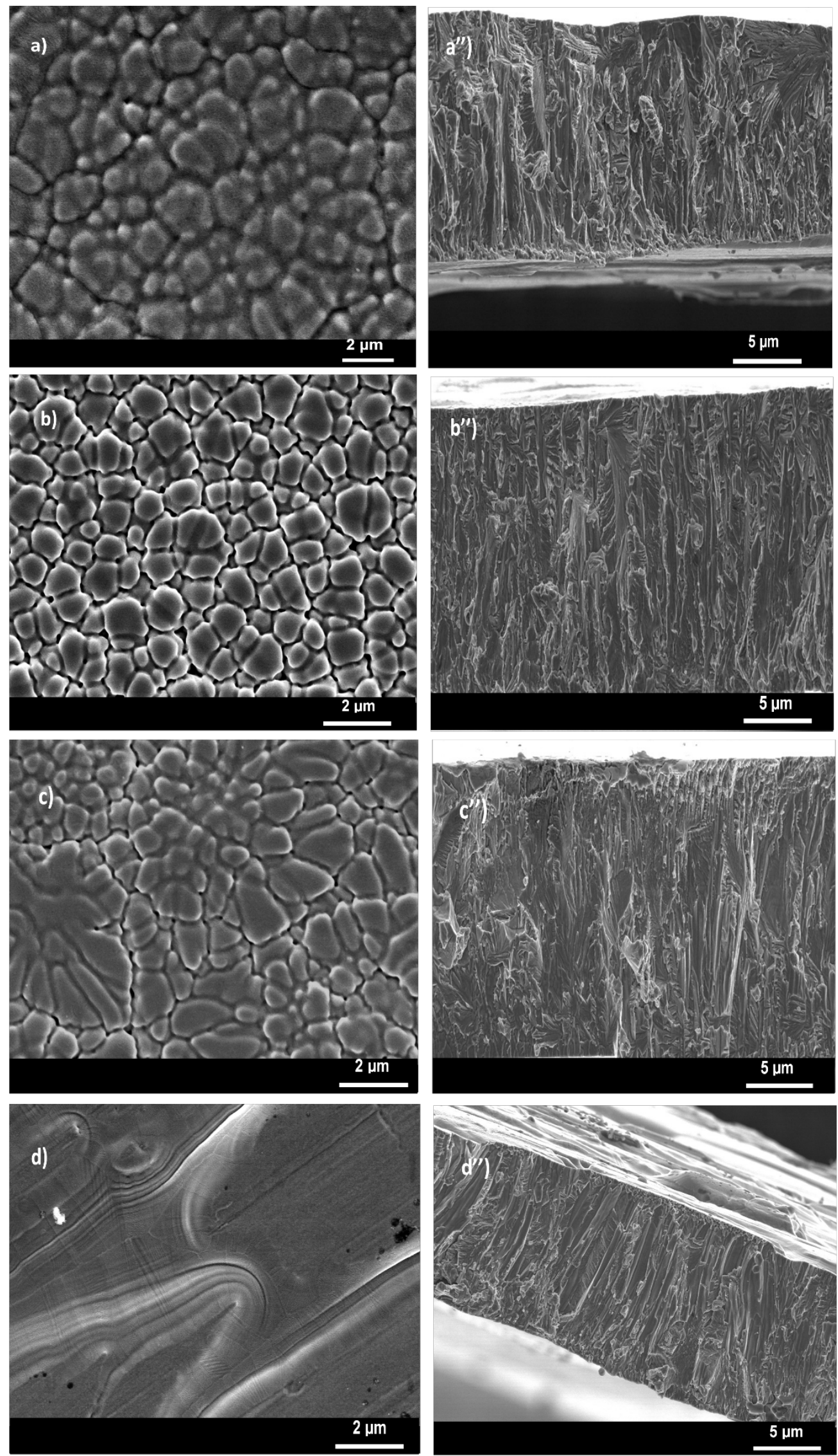

Fig4. SEM micrographs of the free surface (a-d) and the fracture cross section (a' '-d"') of the attained ribbons: (a, a”) $\mathrm{Ni}_{50} \mathrm{Mn}_{36} \mathrm{Sn}_{14}$, (b, b”) $\mathrm{Ni}_{49} \mathrm{Mn}_{36} \mathrm{Sn}_{14} \mathrm{Cu}_{1}$, (c, c”) $\mathrm{Ni}_{48} \mathrm{Mn}_{36} \mathrm{Sn}_{14} \mathrm{Cu}_{2}$ and (d, d”) $\mathrm{Ni}_{50} \mathrm{Mn}_{36} \mathrm{Sn}_{13} \mathrm{Cu}_{1}$. 

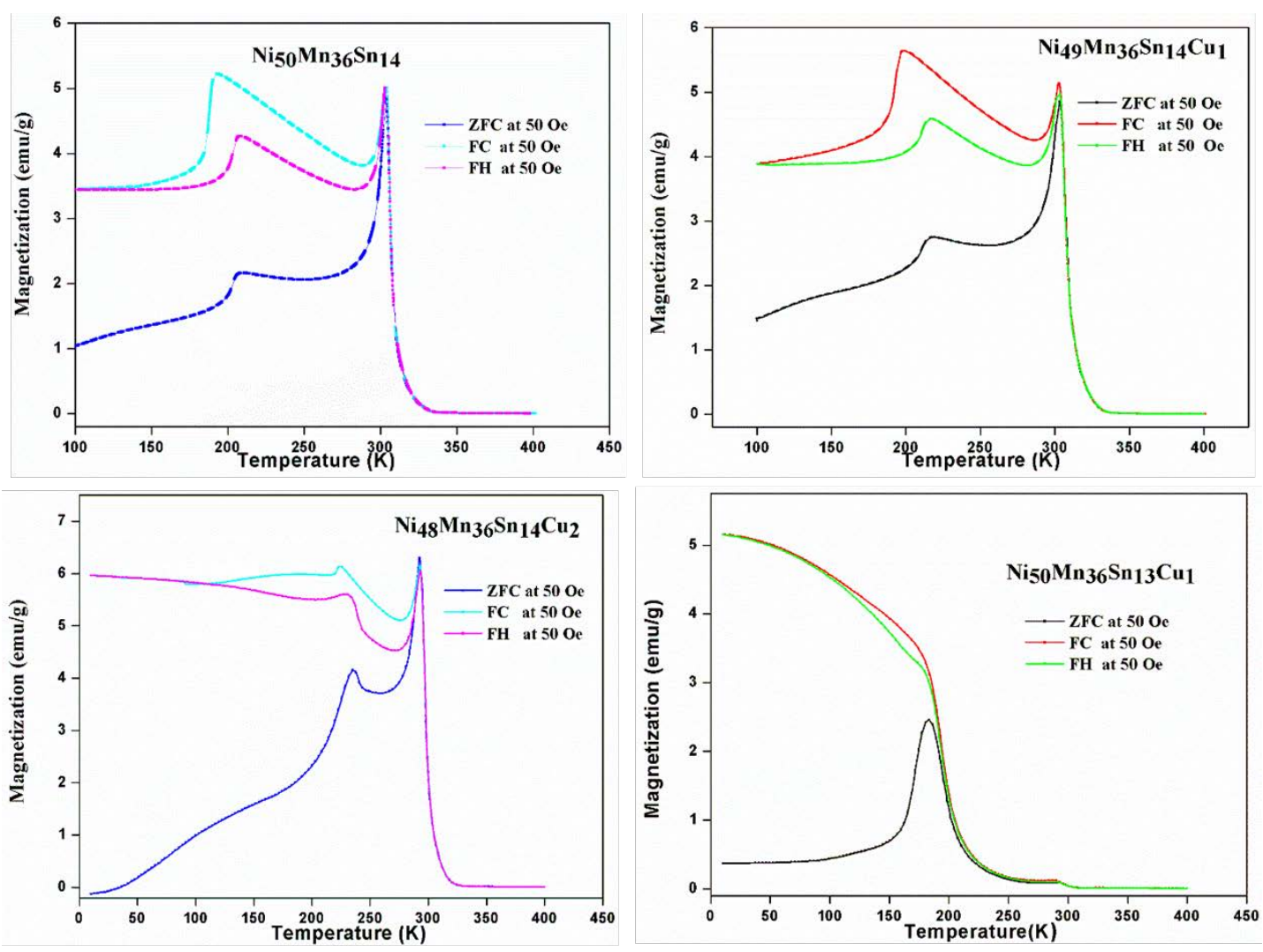

Fig.5 Temperature dependence of the magnetization of all the samples measured at 50 Oe
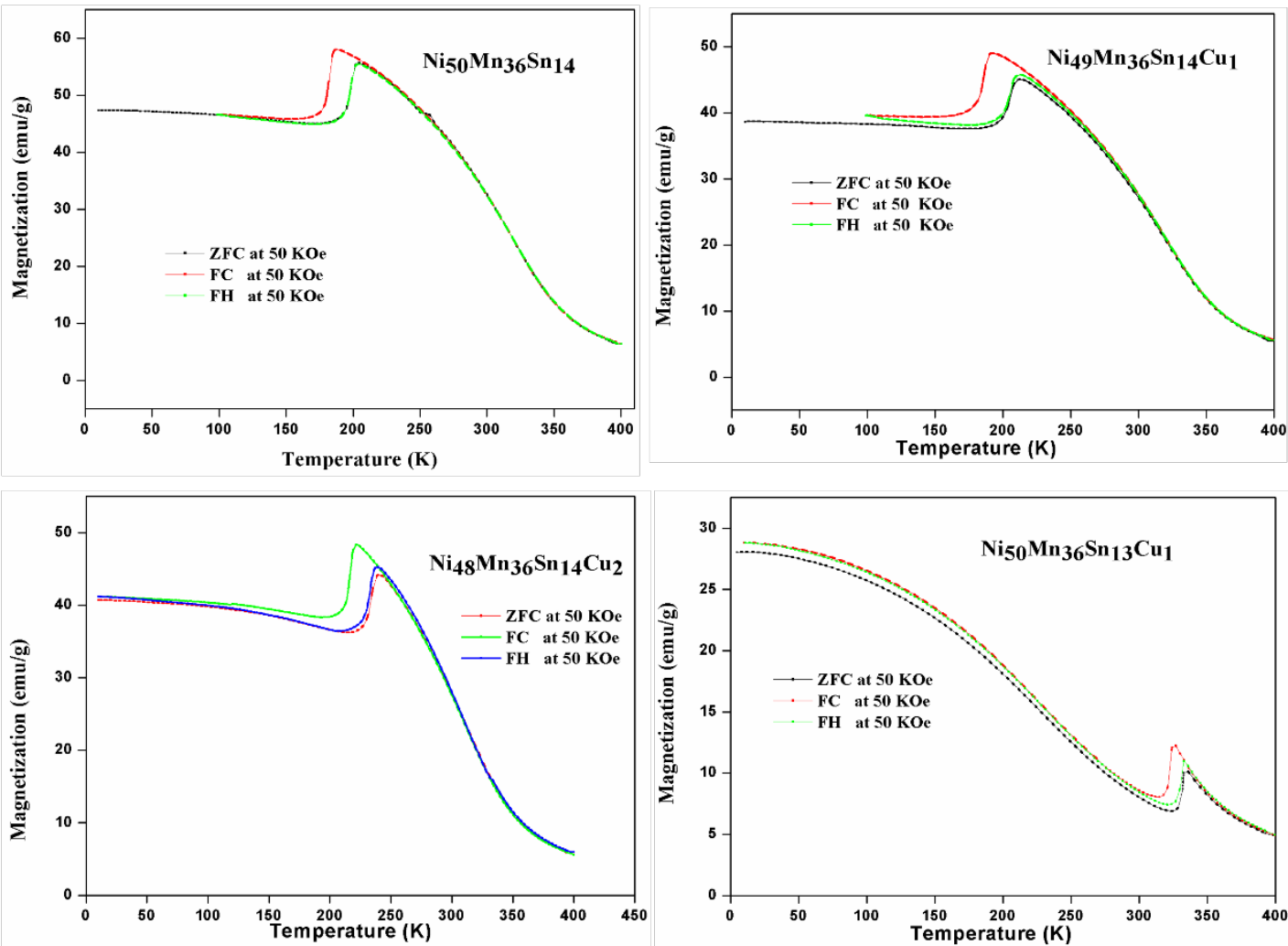

Fig.6 Temperature dependence of the magnetization of all the samples measured at 50 KOe.

Transformation temperatures (Ms, Mf, As, Af) are defined as the intersection of the extrapolation from the linear regions. 

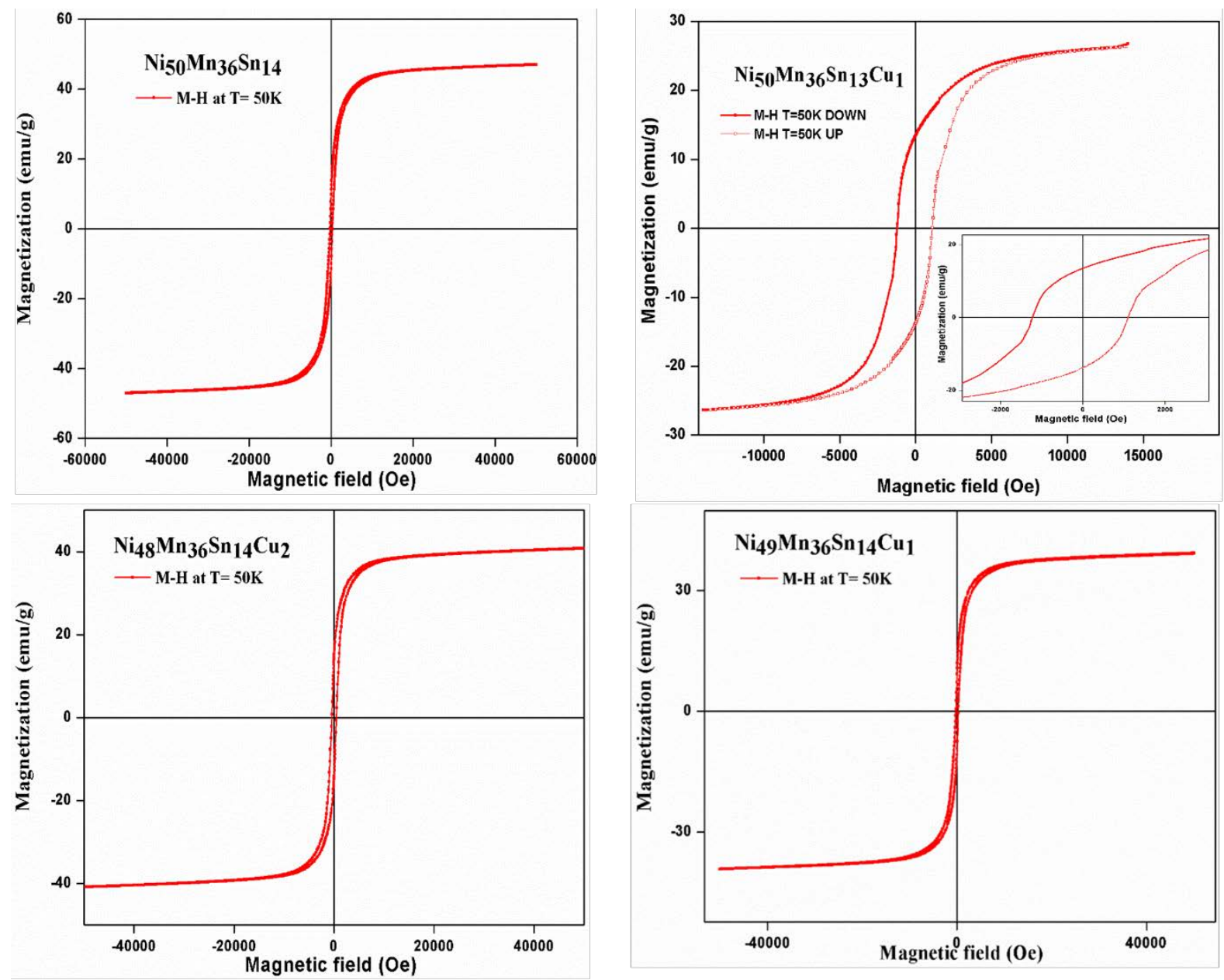

Fig.7 Hysteresis loops measured at $50 \mathrm{~K}$ of $\mathrm{Ni}_{50} \mathrm{Mn}_{36} \mathrm{Sn}_{14}, \mathrm{Ni}_{50} \mathrm{Mn}_{36} \mathrm{Sn}_{14} \mathrm{Cu}_{1}, \mathrm{Ni}_{48} \mathrm{Mn}_{36} \mathrm{Sn}_{14} \mathrm{Cu}_{2}$ and $\mathrm{Ni}_{49} \mathrm{Mn}_{36} \mathrm{Sn}_{14} \mathrm{Cu}_{1}$.

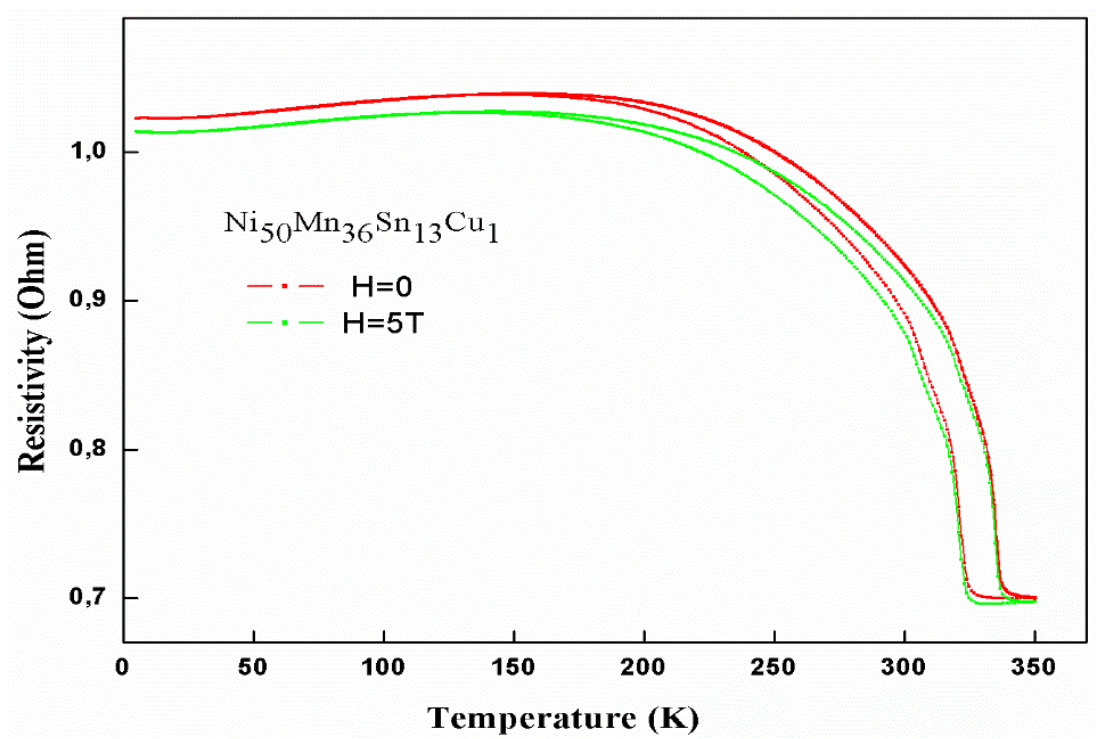

Fig.8 Temperature dependence of electrical resistance measured at $0 \mathrm{~T}$ and $5 \mathrm{~T}$ for $\mathrm{Ni}_{50} \mathrm{Mn}_{36} \mathrm{Sn}_{13} \mathrm{Cu}_{1}$ alloy. 


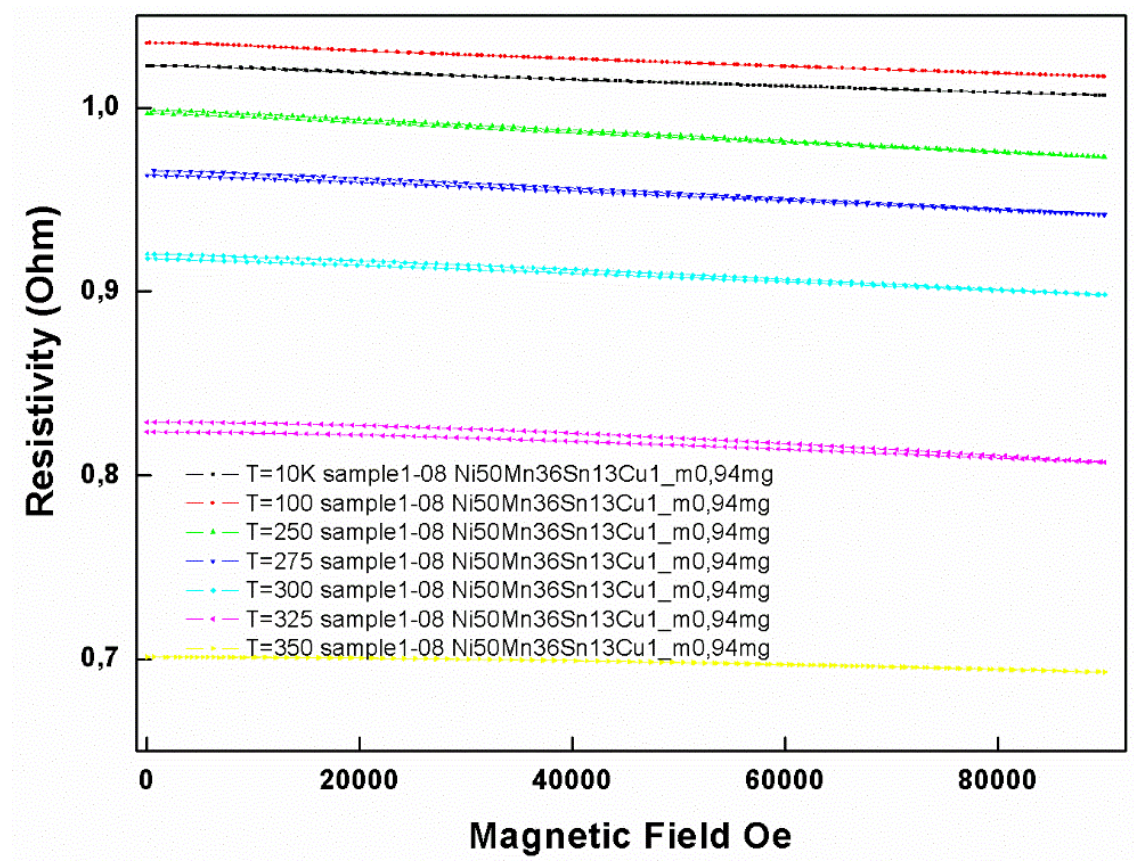

Fig.9 Resistivity dependence of magnetic field (up to $9 \mathrm{~T}$ ) at different temperatures for $\mathrm{Ni}_{50} \mathrm{Mn}_{36} \mathrm{Sn}_{13} \mathrm{Cu}_{1}$. 


\section{Table captions:}

Table 1 Percentage of L21 and B2 order in austenite alloys.

\begin{tabular}{|l|c|c|}
\hline Ribbons & $\begin{array}{l}\text { Percentage of L21 } \\
\text { order }\end{array}$ & $\begin{array}{l}\text { Percentage of B2 } \\
\text { order }\end{array}$ \\
\hline Ni:5nn${ }_{36}$ Sn$_{14}$ & 88 & 87 \\
\hline Ni49Mn36Sn14Cu1 & 85 & 88 \\
\hline Ni48Mn36Sn14Cu2 & 86 & 87 \\
\hline
\end{tabular}

Table 2 Composition of the melt-spun ribbons extracted from the energy dispersive X-ray spectroscopy (EDX).

\begin{tabular}{|l|l|l|l|l|}
\hline $\mathbf{X}, \mathbf{Y}($ at. \%) & Ni (at. \%) & Mn (at. \%) & Sn (at. \%) & Cu (at. \%) \\
\hline $\mathbf{X = 0}$ & 50.82 & 35.75 & 13.43 & 0 \\
\hline $\mathbf{X = 1}$ & 49.43 & 36.06 & 13.38 & 1.13 \\
\hline $\mathbf{X}=\mathbf{2}$ & 48.03 & 36.20 & 13.50 & 2.27 \\
\hline $\mathbf{Y = 1}$ & 50.80 & 34.78 & 12.91 & 1.51 \\
\hline
\end{tabular}

Table 3 The characteristic transformation temperatures (As, Af, Ms and Mf) the enthalpies and entropies obtained from DSC curves upon cooling and heating process.

\begin{tabular}{|c|c|c|c|c|c|c|c|}
\hline Ribbons & $\mathbf{M s} / \mathbf{K}$ & Mf/K & As/K & Af/K & $\mathrm{T}_{\mathbf{0}} / \mathrm{K}$ & $\Delta H / J \cdot g^{-1}$ & $\Delta S / J \cdot g^{-1} \cdot K^{-1}$ \\
\hline Nis0Mn36Sn $_{34}$ & 194.09 & 183 & 198 & 212.2 & 203.17 & $\begin{array}{l}\text { (h) } 1.573 \\
\text { (c) } 1.516\end{array}$ & $\begin{array}{l}\text { (h) } 0.0078 \\
\text { (c) } 0.00758\end{array}$ \\
\hline $\mathrm{Ni}_{49} \mathrm{Mn}_{36} \mathrm{Sn}_{14} \mathrm{Cu} 1$ & 200.41 & 186.3 & 205.25 & 226.65 & 211.53 & $\begin{array}{l}\text { (h) } 1.680 \\
\text { (c) } 1.543\end{array}$ & $\begin{array}{l}\text { (h) } 0.00794 \\
\text { (c) } 0.00729\end{array}$ \\
\hline $\mathrm{Ni}_{48} \mathrm{Mn}_{36} \mathrm{Sn}_{14} \mathrm{Cu}$ & 228.31 & 213 & 230.54 & 245.7 & 237.005 & $\begin{array}{l}\text { (h) } 2.597 \\
\text { (c) } 2.489\end{array}$ & $\begin{array}{l}\text { (h) } 0.00951 \\
\text { (c) } 0.0105\end{array}$ \\
\hline $\mathrm{Ni}_{50} \mathrm{Mn}_{36} \mathrm{Sn}_{13} \mathrm{Cu} 1$ & 325.02 & 316 & 325.63 & 335 & 343.51 & $\begin{array}{l}\text { (h) } 5.122 \\
\text { (c) } 4.559\end{array}$ & $\begin{array}{l}\text { (h) } 0.195 \\
\text { (c) } 0.219\end{array}$ \\
\hline
\end{tabular}


Table 4 Magnetoelastic and magnetostriction constants of $\mathrm{Ni}_{50} \mathrm{Mn}_{36} \mathrm{Sn}_{14}$ andNi $\mathrm{Ni}_{48} \mathrm{Mn}_{36} \mathrm{Sn}_{14} \mathrm{Cu}_{2}$ Heusler alloys.

\begin{tabular}{|c|c|c|c|c|}
\hline Sample & $\begin{array}{l}\text { Magnetoelastic } \\
\text { constant, B11, } \\
\text { erg/cm } \mathbf{c m}^{3}\end{array}$ & $\begin{array}{l}\text { Magnetoelastic } \\
\text { constant, B33, } \\
\text { erg/cm }\end{array}$ & $\begin{array}{l}\text { Magnetostriction } \\
\text { constant, } \lambda s(\text { B11) }\end{array}$ & $\begin{array}{l}\text { Magnetostriction } \\
\text { constant, } \lambda s(\mathrm{~B} 33)\end{array}$ \\
\hline $\mathrm{Ni}_{50} \mathrm{Mn}_{36} \mathrm{Sn}_{14}$ & $1.16 \mathrm{E}+06$ & $1.61 \mathrm{E}+06$ & -4.03 E-06 & -6.70 E-06 \\
\hline $\mathrm{Ni}_{48} \mathrm{Mn}_{36} \mathrm{Sn}_{14} \mathrm{Cu}$ & $3.23 \mathrm{E}+05$ & $3.90 \mathrm{E}+05$ & $-1.35 \mathrm{E}-06$ & -1.62 E-06 \\
\hline
\end{tabular}

